\title{
1 Expression and Purification of a Mammalian Protein: Cytosolic 2 Domain of IRE1 $\alpha$ from Insect Sf21 Cells
}

\author{
3 Amrita Oak ${ }^{1}$, Grace Jansen ${ }^{1}$ and Christina Chan ${ }^{1,2, *}$ \\ 41 Dept. of Chemical Engineering and Materials Science, Michigan State University; \\ 52 Dept. of Biochemistry and Molecular Biology, Michigan State University \\ 6 * Correspondence: krischan@egr.msu.edu;
}

Abstract: Eukaryotic proteins can be expressed in different heterologous systems. However, mammalian proteins in general have specific post-translational processing requirements that may not be fulfilled by a regular bacterial expression system. In this study, we use an insect cell system to express a mammalian protein of interest. Spodoptera frugiperda ( $\mathrm{Sf} 21)$ cells were used in conjunction with a baculoviral expression system to produce the cytosolic domain (CD) of IRE1, an endoplasmic reticulum (ER) stress sensor protein. Inositol Requiring Enzyme 1 (IRE1) is a dual function kinase and endoribonuclease protein that cleaves X-box binding protein (XBP1) mRNA. We used the pFastBac plasmid to insert the coding sequence into a recombinant bacmid shuttle vector which was then used to infect Sf 21 cells. The expressed protein was then purified with an MBPTrap column to obtain $>85 \%$ pure protein.

Keywords: Sf21 cells; baculoviral expression; IRE1; pFastBac; MBP-tagged protein purification

\section{Introduction}

Heterologous expression of proteins is defined as the expression of proteins in an organism that does not naturally express the protein. The different systems in use for such purposes can be broadly classified as bacterial, yeast, insect and mammalian systems. Cells in culture can be manipulated to express the protein of interest in transient or stable mode. Some factors that need to be considered while choosing the expression system are the required yield of the protein, post-translational modifications, functionality, and speed of expression.

Proteins of prokaryotic origin are best expressed in bacterial systems. E. coli can express and adequately process prokaryotic proteins and is the go-to system for cheap, scalable and high yield expression. If the expression of eukaryotic proteins is required, additional factors need to be taken into consideration. The most important factor would arguably be the level of post-translational modifications (PTM) required for a functional form of the protein. Proteins requiring extensive PTMs will not be processed correctly in bacterial systems and will most likely aggregate in inclusion bodies[1]-[3]. Adding a fusion protein tag to the protein of interest may sometimes help to resolubilize the proteins. However, in the interest of saving time and effort, it is advisable to switch to higher eukaryotic systems such as insect or mammalian cells. Another advantage to eukaryotic systems is the presence of extensive protein folding machinery that is vital for the function of the protein [4].

Table 1 compares the different heterologous protein expression systems with respect to the type of protein, post-translational modifications and ease of large-scale production [5]$[10]$. 
Table 1: Characteristics of heterologous protein expression in bacterial, yeast, insect and mammalian cell systems ranked according to desirability

\begin{tabular}{|c|c|c|c|c|}
\hline & Bacterial & Yeast & Insect & Mammalian \\
\hline \multicolumn{5}{|l|}{ Type of protein } \\
\hline Prokaryotic & Y & Y & Y & Y \\
\hline Eukaryotic & $\mathrm{Y}$ & $\mathrm{Y}$ & $\mathrm{Y}$ & Y \\
\hline Secreted & $\mathrm{Y}$ & Y & Y & $\mathrm{Y}$ \\
\hline \multicolumn{5}{|c|}{ Post-translation modifications } \\
\hline Phosphorylation & $\mathrm{Y}$ & $\mathrm{Y}$ & Y & Y \\
\hline Glycosylation & $\mathrm{N}$ & Y & Y & Y \\
\hline Acetylation & $\mathrm{N}$ & Y & Y & Y \\
\hline Acylation & $\mathrm{N}$ & Y & Y & $\mathrm{Y}$ \\
\hline Refolding required? & $\mathrm{Y}$ & $\mathrm{Y}$ & $\mathrm{N}$ & $\mathrm{N}$ \\
\hline \multicolumn{5}{|l|}{ Production } \\
\hline Cell growth & $\begin{array}{l}\text { Rapid } \\
\text { (30 mins) }\end{array}$ & $\begin{array}{c}\text { Rapid } \\
\text { (1.5 hrs) }\end{array}$ & $\begin{array}{c}\text { Moderate } \\
(18 \mathrm{hrs})\end{array}$ & Slow (24hrs) \\
\hline Yield & High & High & Moderate & Low \\
\hline Time to expression & Rapid & Moderate & Moderate & High \\
\hline Cost & Low & Expensive & Expensive & Very expensive \\
\hline Ease of scale-up & Easy & Easy & Difficult & Very difficult \\
\hline
\end{tabular}

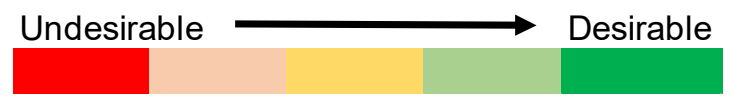

Bacterial systems have desirable characteristics for large scale production but are not able to process and correctly fold proteins requiring extensive PTMs [11]. Depending on the application of the protein, Chinese hamster ovary (CHO) or Human embryonic kidney (HEK 293) cells are typically the system of choice for eukaryotic proteins [12]. This is true, especially for therapeutic proteins or antibodies. However, the yield is very low compared to insect or bacterial cells - typically on the order of $100 \mathrm{mg} / \mathrm{L}$ of expressed protein [13]. The level of protein expression is higher in insect cells up to $100 \mathrm{mg} / \mathrm{L}$ [14], [15].

Insect cells and mammalian systems have a wide range of post-translational modifications. An excellent tool to determine all possible post-translational modifications of a protein of interest is dbPTM (http://dbptm.mbc.nctu.edu.tw/). Insect and mammalian systems are both capable of all PTMs with one exception. Insect cells and mammalian cells have similar phosphorylation and O-linked glycosylation patterns. They can authentically process phosphorylation modifications, partly due to the presence of phosphatases. However, in terms of N-glycosylation, proteins in insect cells are high-mannosylated while mammalian cells have a complex glycosylation pattern [4], [12]. Figure 1 depicts the difference in Nlinked glycosylation patterns in insect cells vs. mammalian cells. Regular insect Sf9 and Sf21 cells will have a high mannose pattern of glycosylation but mimic Sf9 (available from ThermoFisher) cells are engineered to make complex N-glycans with terminal sialic acid. Varied and complex sugars such as $\mathrm{N}$-acetylneuraminic acid, galactose, fucose, mannose are added in mammalian cells in a branched configuration as opposed to the addition of only mannose residues in insect cells. 
73

74

75
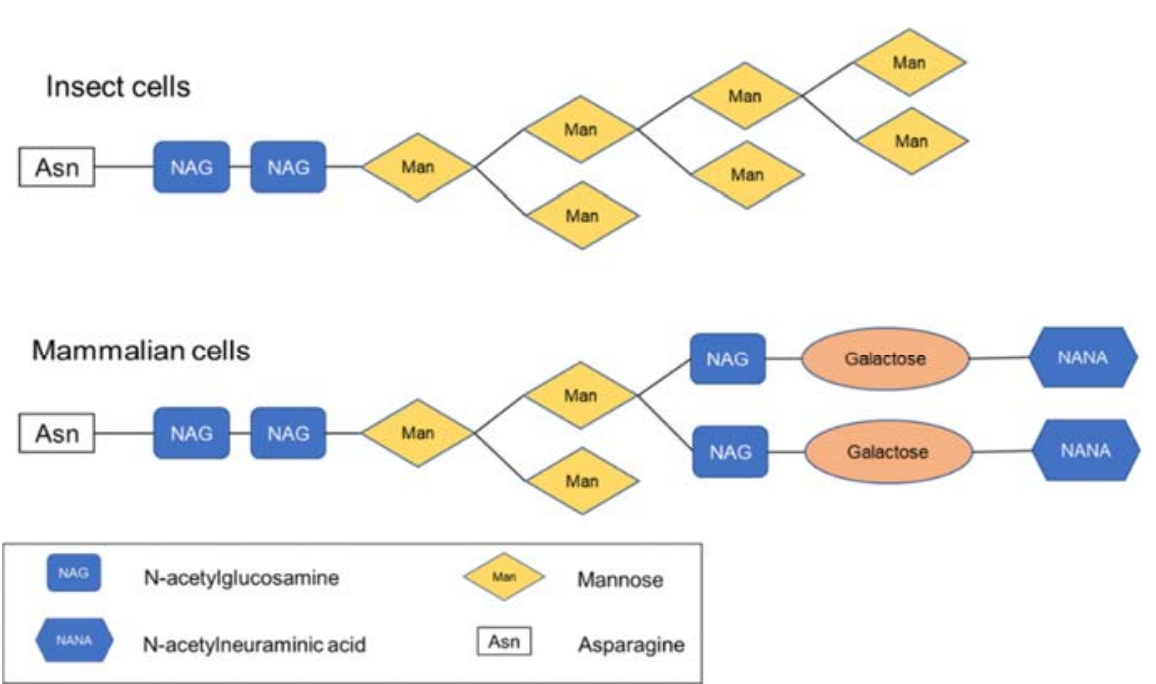

Figure 1: N-linked glycosylation patterns for insect cells and mammalian cells

In this study, we developed a protocol to express the Inositol Requiring Enzyme-1 $\alpha$ $($ IRE1 $\alpha)$ protein, an ER stress sensor. IRE1 is a type I transmembrane protein primarily composed of three domains, the luminal domain, a transmembrane domain and cytosolic domain (CD)[16].

IRE1 $\alpha$ is a bifunctional protein with kinase and endoribonuclease activity on the CD. We have developed a protocol to produce IRE1 $\alpha$-CD (547-977 aa) in insect Sf21 cells using baculovirus expression. IRE1 $\alpha$ has been expressed in E. coli cells in our lab (unpublished data) as well as by other groups[17], [18]. However, IRE1 $\alpha$ expressed in E. coli and yeast systems is in a hyperphosphorylated state[18], [19]. All the purification methods used thus far for purifying this protein have used the 6X His tag. The cell line used was Sf9 [18], [22]. However, there are no detailed methods or protocol papers published for this procedure, that is, using the Sf9 cells and 6X His tag method.

Post-translational modifications for IRE1 were predicted using algorithms developed by the Center for Biological Sequence Analysis, Technical University of Denmark (http://www. cbs.dtu.dk/ [1]. The predicted N-glycosylation, O-glycosylation, C-mannosylation and glycation sites are scored for the likelihood of modification (Table 2). The scores that cross the threshold (which is set by the algorithm at 0.5 ) are denoted as "positive" hits. 
Table 2: Predictions for O-glycosylation, C-mannosylation, $\mathrm{N}$-glycosylation and glycation sites on CD-IRE1.

\begin{tabular}{|c|c|c|c|c|c|c|c|}
\hline \multicolumn{4}{|c|}{ O-glycosylation } & \multicolumn{4}{|c|}{ C-mannosylation } \\
\hline start & end & score & comment & start & end & score & comment \\
\hline$\overline{2}$ & $\overline{2}$ & 0.792 & \#POSITIVE & 191 & 191 & 0.18 & . \\
\hline 3 & 3 & 0.796 & \#POSITIVE & 287 & 287 & 0.271 & $\sigma^{\prime}$ \\
\hline 5 & 5 & 0.791 & \#POSITIVE & & & & \\
\hline 15 & 15 & 0.189 & \multirow{16}{*}{ \#POSITIVE } & \multicolumn{4}{|c|}{ Glycation } \\
\hline 16 & 16 & 0.506 & & start & end & score & comment \\
\hline 24 & 24 & 0.111 & & 22 & 22 & -0.943 & . \\
\hline 38 & 38 & 0.015 & & 28 & 28 & -0.707 & . \\
\hline 61 & 61 & 0.043 & & 53 & 53 & 0.801 & YES \\
\hline 73 & 73 & 0.040 & & 87 & 87 & -0.875 & . \\
\hline 85 & 85 & 0.006 & & 110 & 110 & 0.832 & YES \\
\hline 102 & 102 & 0.018 & & 144 & 144 & -0.529 & . \\
\hline 121 & 121 & 0.110 & & 158 & 158 & 0.699 & YES \\
\hline 126 & 126 & 0.102 & & 160 & 160 & 0.863 & YES \\
\hline 127 & 127 & 0.213 & & 170 & 170 & -0.773 & . \\
\hline 128 & 128 & 0.181 & & 171 & 171 & 0.83 & YES \\
\hline 135 & 135 & 0.052 & & 202 & 202 & -0.95 & . \\
\hline 151 & 151 & 0.107 & & 231 & 231 & -0.962 & . \\
\hline 164 & 164 & 0.034 & & 253 & 253 & -0.799 & . \\
\hline 178 & 178 & 0.107 & & 265 & 265 & 0.806 & YES \\
\hline 180 & 180 & 0.741 & \multirow{11}{*}{$\begin{array}{l}\text { \#POSITIVE } \\
\text { \#POSITIVE }\end{array}$} & 273 & 273 & -0.94 & . \\
\hline 183 & 183 & 0.643 & & 282 & 282 & -0.878 & . \\
\hline 188 & 188 & 0.111 & & 291 & 291 & -0.83 & \\
\hline 198 & 198 & 0.148 & & & & & \\
\hline 206 & 206 & 0.026 & & \multicolumn{4}{|c|}{ N-glycosylation } \\
\hline 208 & 208 & 0.047 & & start & end & score & comment \\
\hline 213 & 213 & 0.013 & & 204 & 204 & 0.5427 & + \\
\hline 223 & 223 & 0.070 & & & & & \\
\hline 226 & 226 & 0.040 & & & & & \\
\hline 232 & 232 & 0.064 & & & & & \\
\hline 245 & 245 & 0.252 & & & & & \\
\hline 276 & 276 & 0.510 & \#POSITIVE & & & & \\
\hline 288 & 288 & 0.454 & & & & & \\
\hline 300 & 300 & 0.102 & & & & & \\
\hline 300 & 300 & 0.102 & & & & & \\
\hline
\end{tabular}

\section{Experimental Design}

\subsection{Materials}

All the materials are listed separated by each sub-section of the procedure.

Cloning of IRE1 $\alpha$-CD into pFastBac plasmid

i. pFastBac His6 MBP N10 TEV LIC cloning vector (4C) (Addgene plasmid \#30116)

ii. $\quad$ SspI-HF (New England Biolabs, cat \# R3132S)

iii. CutSmart buffer (New England Biolabs cat\# B7204S)

iv. QIAquick PCR Purification Kit (Qiagen, cat\# 28104)

v. Deoxynucleotide (dNTP) set includes dGTP, dCTP (New England Biolabs, cat \# N0446S)

vi. Bovine Serum Albumin (BSA), Molecular Grade (New England Biolabs, cat\# B9000S)

vii. T4 DNA Polymerase (New England Biolabs, cat\# M0203S)

viii. Q5 High Fidelity 2X Master Mix (New England Biolabs, cat\# M0492S)

ix. OneShot Top10 chemically competent E. coli DH5 $\alpha$ (ThermoFisher, cat\# C404003)

x. Luria Broth (Sigma-Aldrich, cat\# L3397)

xi. Luria Agar (Sigma-Aldrich, cat\# L3272)

xii. $\quad$ LB agar plates containing ampicillin (Sigma-Aldrich, cat \# L5667-10EA)

Preparation of recombinant bacmid xiii. MAX Efficiency E. coli DH10Bac competent cells (ThermoFisher cat\# 10361012) 
122

123

124

125

126

127

128

129

130

|131

132

133

134

135

136

137

138

139

140

141

142

143

144

145

146

147

148

149

150

151

152

153

xiv. Antibiotics and their stock solutions are listed in Table 3. Aliquot and store at $-20^{\circ} \mathrm{C}$.

Table 3: Antibiotic concentrations and stock solutions

\begin{tabular}{|c|c|c|c|c|}
\hline Component & Dissolve in & $\begin{array}{l}\text { Company (Cat. } \\
\text { No) }\end{array}$ & Stock conc. & Special considerations \\
\hline Kanamycin & Water & Sigma (60615) & $50 \mathrm{mg} / \mathrm{mL}$ & \\
\hline Tetracycline & Ethanol & Sigma (87128) & $10 \mathrm{mg} / \mathrm{mL}$ & Light sensitive \\
\hline Gentamicin & Water & Sigma (G1914) & $7 \mathrm{mg} / \mathrm{mL}$ & \\
\hline$X$-gal ${ }^{* *}$ & $\begin{array}{l}\text { Dimethyl } \\
\text { formamide }\end{array}$ & Sigma (XGAL-RO) & $20 \mathrm{mg} / \mathrm{mL}$ & $\begin{array}{l}\text { Light sensitive, DO NOT } \\
\text { filter sterilize, Make solution in a } \\
\text { glass vial or polypropylene tube }\end{array}$ \\
\hline IPTG & Water & Sigma (I6758) & $200 \mathrm{mg} / \mathrm{mL}$ & Filter sterilize \\
\hline
\end{tabular}

** There are other options for X-gal such as Bluo-gal (ThermoFisher, cat \# 15519028). It is more expensive but more sensitive and turns a deeper, more obvious blue that aids in colony identification**

Xv. $\quad$ S.O.C medium (ThermoFisher cat\# 15544034)

xvi. PureLink HiPure Plasmid Miniprep Kit (Invitrogen, cat\# K210002)

Transfection of recombinant bacmid into Sf21 cells

i. Sf-900-III serum-free media (ThermoFisher, cat\# 12658019)

ii. Cellfectin II reagent (ThermoFisher, cat\# 10362100)

iii. Gelcode Blue Stain Reagent (ThermoFisher, cat\# 24590)

iv. IRE1 $\alpha$ (14C10) Rabbit mAb (Cell Signaling Tech, cat\# 3294)

Protein purification using MBPTrap column

v. Xtractor cell lysis buffer (Takara, cat\# 635671)

vi. cOmplete, Mini, EDTA-free protease inhibitor cocktail (Sigma, cat\# 11836170001)

vii. MBPTrap HP column (GE, cat\# 28-9187-78)

viii. $\quad$ D-(+)- Maltose monohydrate (Sigma, cat\# 63418-25G)

ix. Tris-Cl (Sigma, cat \# 10812846001)

x. $\mathrm{NaCl}$ (Sigma, cat \# S3014)

xi. Dithiothreitol (DTT) (Sigma, cat\# DTT-RO)

xii. EDTA (Sigma, cat \# 324504)

xiii. Phosphate buffered saline (PBS) (Sigma, cat\# P7059-1L)

xiv. Binding buffer for MBPTrap HP column: $20 \mathrm{mM}$ Tris-HCl, $200 \mathrm{mM} \mathrm{NaCl}, 1 \mathrm{mM}$ DTT, 1 mM EDTA, pH 7.4

xv. Elution Buffer for MBPTrap HP column: Binding buffer $+10 \mathrm{mM}$ maltose

xvi. Regeneration buffer: $0.5 \mathrm{M} \mathrm{NaOH}$

\section{Procedure}

Figure 2 depicts a flowchart of the steps involved in the expression and purification of IRE1 $\alpha-C D$ in Sf 1 cells using baculoviral vectors. The procedure is divided into 5 subunits. The time required for each subunit is indicated in brackets in the left column (Figure 2). 


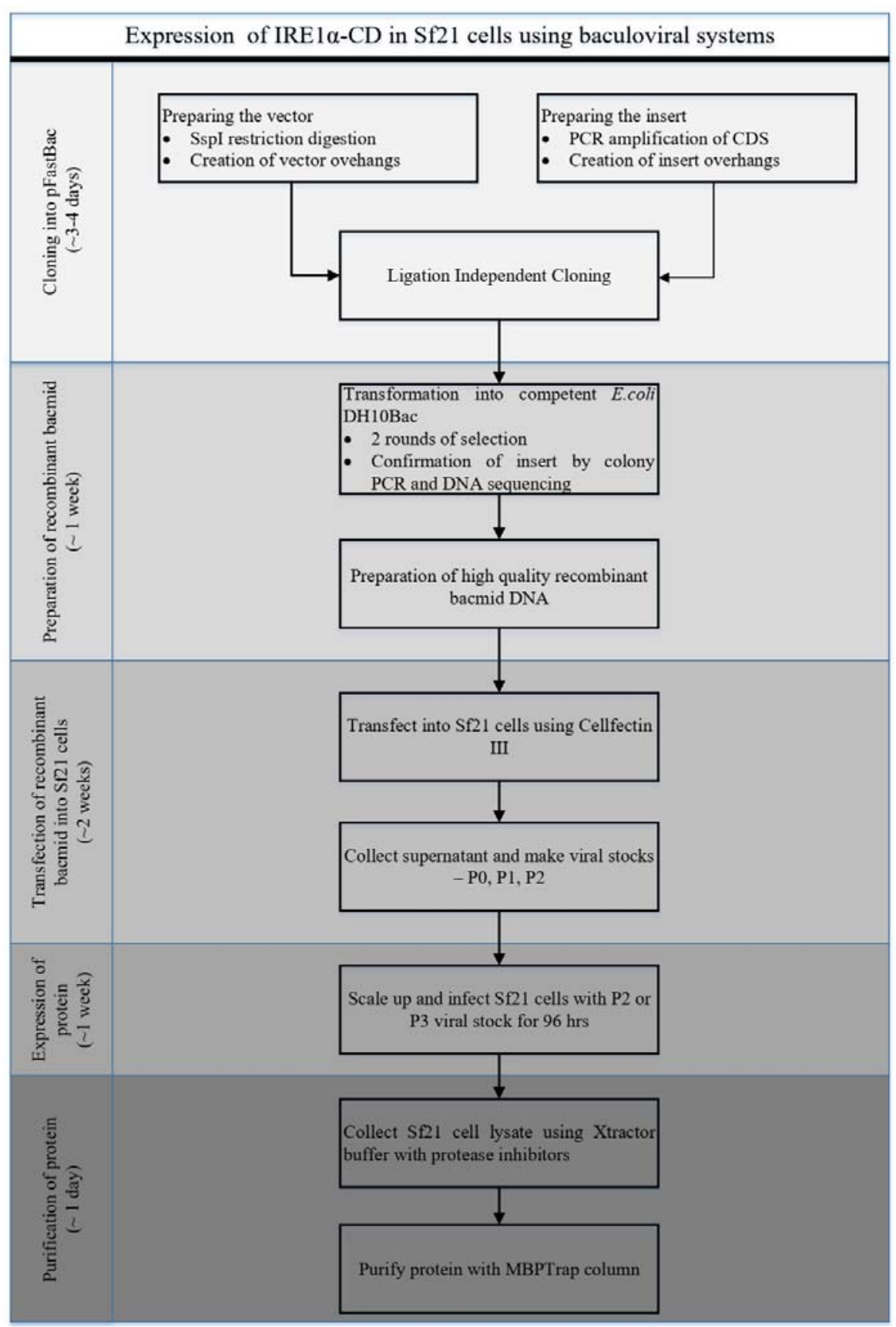

Figure 2: Flowchart for all the steps involved in the expression and purification of proteins from Sf21 cells

\subsection{Cloning of IRE $1 \alpha-C D$ into pFastBac plasmid}

\section{Note:}

pFastBac His6 MBP N10 TEV LIC cloning vector (4C) was a gift from Scott Gradia (Addgene plasmid \#30116; http://n2t.net/addgene:30116; RRID: Addgene_30116). Another version of this plasmid (5C) is available so that two proteins can be expressed simultaneously. The sequence for IRE1 $\alpha$ - CD was obtained from NCBI (Gene id: 2081). Primers were designed to clone the CD fragment from 547 aa-977 aa from a pCDNA-hIRE1 plasmid containing a full-length IRE1 coding sequence. 
Table 4: PCR primers for insertion of IRE1-CD (547aa-977aa) into pFastBac plasmid

\begin{tabular}{|c|c|}
\hline CD_IRE1_forward & $5^{\prime}$ - TACTTCCAATCCAATGCAGGCAGCAGCCCCTCCCTGGAAC-3' \\
\hline CD_IRE1_reverse & 5' - TTATCCACTTCCAATGTTATTAGAGGGCGTCTGGAGTCAC-3' \\
\hline
\end{tabular}

167

168

169

170

171

172

173

174

175

176

177

178

179

180

181

182

183

184

185

186

187

188

189

190

191

192

193

Table 4 shows the primers designed for the insertion of IRE1 $\alpha$-CD into the empty pFastBac plasmid. The underlined tag on each primer is to facilitate ligation independent cloning (LIC) and is specific to the pFastBac backbone. The rest of the primer is specific to the insert coding sequence (CDS). The LIC technique makes use of the endonuclease activity of T4 DNA polymerase to generate sticky overhangs for ligation between the vector plasmid and insert DNA. This technique avoids the use of ligases.

\section{Protocol:}

Preparing the vector pFastBac plasmid

i. Linearize the plasmid with SspI-HF (NEB) (Table 5). The high-fidelity (HF) versions of restriction enzymes are faster and more efficient. Incubate at $37^{\circ} \mathrm{C}$ for 15 mins -2 hrs to completely digest all the plasmid DNA. Heat inactivation is performed for 20 mins at $65^{\circ} \mathrm{C}$.

Table 5: Restriction digestion with SspI-HF

\begin{tabular}{|l|l|l|}
\hline Component & Amount & Volume $(\mu \mathrm{L})$ \\
\hline $\begin{array}{l}\text { pFastBac plasmid DNA } \\
(250 n g / u L)\end{array}$ & $1 \mu \mathrm{g}$ & 4 \\
\hline 10X CutSmart buffer & Final concentration 1X & 5 \\
\hline SspI-HF & 10 units & 1 \\
\hline Water & Make up to $50 \mu \mathrm{L}$ & 40 \\
\hline
\end{tabular}

ii. Use a PCR purification kit (QIAquick) to purify the large linearized fragment of plasmid DNA.

iii. To create $\mathrm{pFastBac}$ vector overhangs, mix the following components in PCR tubes, the order of addition is as listed (T4 DNA polymerase is added last) (Table 6). Incubate at $12^{\circ} \mathrm{C}$ for 30 minutes followed by heat inactivation at $75^{\circ} \mathrm{C}$ for 20 minutes.

Table 6: Mix to create pFastBac vector overhangs

\begin{tabular}{|l|l|l|}
\hline \multicolumn{1}{|c|}{ Reagent } & Final conc. & Volume $(\mu \mathrm{L})$ \\
\hline 10x NEB 2.1 & $1 \mathrm{x}$ & 4 \\
\hline Eluted linearized pFastBac DNA & $10-50 \mathrm{ng} / \mu \mathrm{L}$ & $20-30$ \\
\hline dGTP $(100 \mathrm{mM})$ & $2.5 \mathrm{mM}$ & 1 \\
\hline DTT $(100 \mathrm{mM})$ & $5 \mathrm{mM}$ & 2 \\
\hline BSA $(10 \mathrm{ug} / \mathrm{ul})$ & $0.25 \mu \mathrm{g} / \mu \mathrm{L}$ & 0.6 \\
\hline T4 DNA polymerase & $0.075 \mathrm{units} / \mu \mathrm{L}$ & 1 \\
\hline Sterile dH2O to $40 \mathrm{ul}$ & & \\
\hline
\end{tabular}

Preparing the insert IRE $1 \alpha-C D$

iv. Set up a PCR to amplify the IRE1 $\alpha$-CD insert using the primers in Table 4 as outlined in Table 7. Confirm amplification by running the PCR product on a $1.5 \%$ agarose gel. 
Table 7: PCR mix for preparing IRE1 $\alpha$-CD insert

\begin{tabular}{|l|l|}
\hline Component & Volume $(\mu \mathrm{L})$ \\
\hline Q5 2X Master Mix & 25 \\
\hline CD_IRE1_forward primer $(10 \mu \mathrm{M})$ & 2 \\
\hline CD_IRE1_reverse primer $(10 \mu \mathrm{M})$ & 2 \\
\hline pCDNA-hIRE1 $(50 \mathrm{ng} / \mu \mathrm{L})$ & 1 \\
\hline Nuclease free water $($ make up to $50 \mu \mathrm{L})$ & 20 \\
\hline
\end{tabular}

195

196

197

198

199

200

201

202

203

204

205

206

207

208

209

The PCR program should be run for $98^{\circ} \mathrm{C} 1 \mathrm{~min}$, followed by 35 cycles of $98^{\circ} \mathrm{C}$ for 30 sec, $61^{\circ} \mathrm{C}$ for $10 \mathrm{sec}, 72^{\circ} \mathrm{C}$ for $90 \mathrm{sec}$, and a final extension of $72^{\circ} \mathrm{C}$ for $5 \mathrm{mins}$.

v. Create the insert overhangs in a way similar to the vector overhangs in the presence of dCTP (instead of dGTP).

vi. After heat inactivation, mix both vector and insert together (1:3 ratio). The total volume of the combined vector and insert should be between 5-10 uL. Incubate for 5 mins at room temperature and then add $1 \mathrm{uL}$ of $25 \mathrm{mM}$ EDTA followed by another incubation for 5 mins.

vii. Transform $2 \mu \mathrm{L}$ of this mixture into competent OneShot Top10 E. coli DH5 $\alpha(100 \mu \mathrm{L})$, spread onto LB agar plates containing $100 \mu \mathrm{g} / \mathrm{mL}$ ampicillin and incubated at $37^{\circ} \mathrm{C}$ for 16-24 hrs.

viii. Select individual colonies (5-10) and prep the plasmid DNA. Confirm the insertion of IRE1 $\alpha$ - CD by DNA sequencing using primers specific to the IRE1 $\alpha-C D$ sequence (seq for- 5' - aagcagctccagttcttccaggac-3')

\subsection{Preparation of recombinant bacmid}

Note:

Once the insert has been cloned into the pFastBac empty plasmid, it needs to be transformed into E. coli $\mathrm{DH} 10 \mathrm{Bac}$ cells to form the recombinant bacmid. E. coli DH10Bac competent cells are sold by ThermoFisher. The genotype is F-mcrA $\Delta$ (mrr-hsdRMSmcrBC) $\Phi 80$ lacZ $\Delta$ M15 $\Delta$ lac X74 recA1endA1 araD139 $\Delta$ (ara, leu)7697 galU galK $\lambda$ - rps L nupG /pMON14272 / pMON7124. DH10Bac cells have a baculovirus shuttle vector and a helper plasmid. This machinery is required for the generation of recombinant bacmid after transformation of pFastBac-IRE $1 \alpha-C D$ into the cells. The baculovirus shuttle vector (bMON14272) also encodes kanamycin resistance, and the helper plasmid (pMON7142) has tetracycline resistance. The presence of the $\Phi 80$ lacZ $\Delta \mathrm{M} 15 \Delta$ lac marker enables the use of blue/white colony screening to determine integration of the insert into the bacmid.pFastBac has the $\operatorname{Tn} 7$ element which includes the polyhedrin promoter, the gene of interest and gentamicin resistance.

It is also possible to use regular E. coli DH10Bac cells and make them chemically competent (see Supplemental file).

\section{Protocol:}

i. $\quad$ Dissolve LB agar powder in water and autoclave at $121^{\circ} \mathrm{C}$ for 15 mins.

ii. Let it cool to $55^{\circ} \mathrm{C}$ (there should be no lumps of agar).

iii. Add all the antibiotics and chemicals in the working concentrations listed in Table 8.

Table 8: Working concentrations of antibiotics

\begin{tabular}{|l|l|l|l|}
\hline Component & Stock conc. & $\begin{array}{l}\text { Working } \\
\text { conc. }\end{array}$ & Dilution \\
\hline Kanamycin & $50 \mathrm{mg} / \mathrm{mL}$ & $50 \mu \mathrm{g} / \mathrm{mL}$ & $1: 1000$ \\
\hline Tetracycline & $10 \mathrm{mg} / \mathrm{mL}$ & $10 \mu \mathrm{g} / \mathrm{mL}$ & $1: 1000$ \\
\hline
\end{tabular}


iv. Let harden, store at $4^{\circ} \mathrm{C}$ in the dark.

v. Thaw a vial of competent $E$. coli $\mathrm{DH} 10 \mathrm{Bac}$ cells on ice in a $15 \mathrm{~mL}$ round bottom sterile polypropylene tube.

*Do not use $1.7 \mathrm{~mL}$ or $2 \mathrm{~mL}$ microcentrifuge tube*

vi. Add 100ng pFastBac-IRE1-CD plasmid DNA to the vial.

vii. Incubate on ice for $\mathbf{3 0}$ mins.

viii. Heat shock for $\mathbf{4 5} \mathrm{s}$ at $\mathbf{4 2}^{\circ} \mathrm{C}$.

ix. Transfer tubes back on ice and chill for 5 mins.

x. Add $900 \mu \mathrm{L}$ SOC medium.

xi. Incubate tubes in a shaking incubator, $37^{\circ} \mathrm{C}$ at $200 \mathrm{rpm}$ for at least $\mathbf{4} \mathbf{h r s}$.

*This $4 \mathrm{hr}$ long outgrowth step is necessary to allow the bacteria to generate the antibiotic resistance proteins encoded on the plasmid backbone*

xii. Make three 10 -fold serial dilutions of $800 \mu \mathrm{L}$ cells. Plate $100 \mathrm{uL}$ of each dilution onto LB plates with kanamycin, tetracycline, gentamicin, X-gal and IPTG.

xiii. Incubate plates at $37^{\circ} \mathrm{C}$ for $\mathbf{4 8} \mathbf{~ h r s}$ to allow enough time for colony formation and color development. Pick white colonies.

*Do not pick colonies before 48 hrs because it may be difficult to distinguish between white and blue colonies*

*Pick colonies that are large and well isolated. Avoid picking colonies that are gray or darker in the center as they may contain a mixture of empty bacmid and recombinant bacmid*

xiv. Replate selected colonies for an additional round of selection on fresh LB agar plates overnight at $37^{\circ} \mathrm{C}$.

$\mathrm{xv}$. Once the white phenotype is confirmed, inoculate in LB media with kanamycin, gentamicin, and tetracycline and grow overnight.

xvi. Isolate recombinant bacmid DNA using Purelink HiPure Plasmid Kit by Invitrogen with a modified protocol (see Supplemental file).

\subsection{Transfection of recombinant bacmid into Sf21 cells}

Note:

$\mathrm{Sf} 21$ cells are suspension cells grown at $28^{\circ} \mathrm{C}$, without the need for $\mathrm{CO}_{2}$ incubators. They are grown in Sf-900 III media. The media can be supplemented, if needed, with serum but bovine serum should not be used (fetal bovine serum (FBS) is preferred). The serum needs to be inactivated to inactivate complement fragments that can inactivate baculoviruses. Transfection reagents can be lipid based (e.g. cellfectin, fugene). Calcium chloride can be used for baculovirus transfection, but it has less efficiency than lipid-based reagents.

\section{Protocol:}

Transfection of bacmid into Sf21 cells

i. A day before transfection, passage $\mathrm{Sf} 21$ cells so that they are at a density of $3 \times 10^{5}$ cells $/ \mathrm{mL}$.

*Actively dividing cells have a higher transfection efficiency and produce more protein*

ii. Plate cells at a concentration of $8 \times 10^{5}$ cells/well of a 24-well plate.

iii. Allow the cells to attach for $1 \mathrm{hr}$ and replace media with fresh media (without FBS).

iv. Use $2 \mu \mathrm{g}$ of bacmid DNA per well. Dilute in $75 \mu \mathrm{L}$ of Sf 900-III media. Incubate for 15 mins. 
280

281

282

283

284

285

286

287

288

289

290

291

292

293

294

295

296

297

298

299

300

301

302

303

304

305

306

307

308

309

310

311

312

313

314

315

316

317

318

319

320

321

322

323

324

325

326

327

328 v. Use $8 \mu \mathrm{L}$ of cellfectin II in $75 \mu \mathrm{L}$ media. Incubate for 15 mins.

*Make sure the cellfectin II is mixed thoroughly before use, but do not vortex the tube*

vi. Mix together the two tubes and incubate for 15-30 mins.

vii. Add mixture dropwise to the wells of the 24-well plate.

viii. 24 hrs later, replace transfection media with fresh SF-900 III media containing 10\% FBS.

*Serum proteins in FBS act as substrates for proteases*

ix. Check for signs of infection (SIF) after $24 \mathrm{hrs}$ up to $96 \mathrm{hrs}$.

*SIF may not be obvious in P0 infection so continue infection for 5 days and collect the supernatant and re-infect for 5 more days to amplify the viral stock*

x. After changing media, collect supernatant after every $24 \mathrm{hrs}$ for 24, 48, 72 and $96 \mathrm{hrs}$. This supernatant is the $\mathrm{P} 0$ viral stock. Store at $4^{\circ} \mathrm{C}$ in the dark.

xi. Use the P0 viral stock to infect newly plated Sf21 cells to generate P1 stock. Add 150 $\mu \mathrm{L}$ of P0 stock dropwise on top of the cells (plated in a 6-well plate), gently swirl a few times and incubate the plate at $28^{\circ} \mathrm{C}$.

xii. Look for SIF in 24 hours post infection time. After 5 days, collect only P1 viruses with SIF and store viral stocks in the dark at $4^{\circ} \mathrm{C}$.

xiii. In a similar fashion, collect P2, P3 and P4 stocks for increased baculoviral titer with an increasing number of cells infected (6-well plate $\rightarrow 150 \mathrm{~cm}$ dish $\rightarrow$ T25 flask). Store all at $4^{\circ} \mathrm{C}$ protected from light.

\section{Scale-up of heterologous protein expression}

i. Seed Sf21 cells in a T75 (vented) flask as described in the transfection procedure. Make sure they are actively dividing cells in the log phase of growth.

ii. Add $150 \mu \mathrm{L}$ of the collected P1 stock.

iii. Incubate at $27^{\circ} \mathrm{C}$ for 5 days or until $30-40 \%$ of the cells have lysed.

iv. Collect cells as well as supernatant. This will be the P2 viral stock.

v. Use P2 viral stock to infect spinner flasks with Sf21 cells.

vi. If no signs of infection are observed, infect Sf21 cells with the P2 stock of baculoviruses and collect the P3 viral stock (see Figure 5 for SIF). We concentrated the baculovirus viral supernatants with successive passages $(\mathrm{P} 1, \mathrm{P} 2, \mathrm{P} 3)$ and used the passage that gave us visible signs of infection at $24 \mathrm{hrs}$ with expression of protein. The viral titer (expressed as plaque-forming units $/ \mathrm{mL}$ or $\mathrm{pfu} / \mathrm{mL}$ ) can also be determined with a plaque assay. Briefly, cells in a tissue culture dish are infected and overlayed with agarose. After the cells are grown for about 10 days, the plaques can be counted to determine the $\mathrm{pfu} / \mathrm{mL}$ concentration.

\subsection{Purification of MBP fusion protein}

Note:

For this protocol, use Sf21 cells infected with P3 stock of baculovirus for 96 hrs. The cell pellet is collected and lysed with Xtractor buffer, and an MBPTrap column is used to extract MBP-tagged IRE1 $\alpha$-CD. The MBP tag can be cleaved from the protein by incubating with 1 unit of AcTEV protease (ThermoFisher, cat\# 12575015) for $1 \mathrm{hr}$ at $30^{\circ} \mathrm{C}$ for each $3 \mu \mathrm{g}$ protein.

\section{Protocol:}

i.Prepare Xtractor buffer with protease inhibitor of choice. In this purification protocol, we used cOmplete EDTA free protease inhibitor cocktail.

ii.Pellet Sf21 cells at $100 \mathrm{x}$ g for $15 \mathrm{mins}$, remove supernatant media and wash pellet once with phosphate buffered saline (PBS). Add $5 \mathrm{~mL}$ Xtractor buffer to $1 \mathrm{~g}$ cell pellet. 
329

330

331

332

333

334

335

336

337

338

339

340

341

342

343

344

345

346

347

348

349

350

351

352

353

354

355

356

357

358

iii.Mix vigorously by vortexing and rock at room temperature for 15-30 mins. Make sure that cell lysis is complete by observing under the microscope.

iv.Centrifuge at $16,000 \mathrm{~g}$ for 20-30 mins to pellet the cell debris.

v.Take the clarified supernatant and filter through a $0.22 \mu \mathrm{m}$ filter immediately before loading onto the MBPTrap HP column.

vi.Prior to loading the clarified lysate, equilibrate the MBPTrap HP column with 7 column volumes $(\mathrm{CV})$ of binding buffer at a flow rate of $1 \mathrm{~mL} / \mathrm{min}$

vii.Load clarified lysate onto the column. The binding capacity of the $1 \mathrm{~mL}$ MBPTrap HP column is protein dependent but can bind approximately to $5 \mathrm{mg}-7 \mathrm{mg}$ of MBP-tagged protein. The flow rate should be decreased to $0.5 \mathrm{~mL} / \mathrm{min}$.

viii. Wash with $10 \mathrm{CV}$ of binding buffer at a flow rate of $1 \mathrm{~mL} / \mathrm{min}$. If real-time A280 readings are possible, wash until no discernible absorbance at $280 \mathrm{~nm}$ is observed.

ix.Add $5 \mathrm{CV}$ of elution buffer at a reduced flow rate of $0.5 \mathrm{~mL} / \mathrm{min}$, and assay elute fractions to determine fractions with the highest concentration of the protein of interest with a Bradford or BCA assay.

x.Regenerate the column with $3 \mathrm{CV}$ distilled water followed by $3 \mathrm{CV}$ of $0.5 \mathrm{M} \mathrm{NaOH}$. Wash away the $\mathrm{NaOH}$ with $5 \mathrm{CV}$ distilled water. The column is now ready to be used again.

\section{Expected Results}

The pFastBac- IRE1 $\alpha$-CD plasmid features are shown in Figure 3 [20]. IRE1 $\alpha$-CD is fused to the C-terminus of an MBP protein under the polyhedrin promoter. A $6 \mathrm{X}$ His tag is also present at the N-terminal of the MBP protein. The MBP protein and IRE1 $\alpha$-CD coding sequences are separated by a Tobacco Etch Virus (TEV) protease site. The plasmid has an ampicillin (amp) and gentamicin (gent) selection marker for selection during the preparation of recombinant bacmid. The pFastBac backbone has a Tn7att transposition element that guides the insertion of the coding sequence into the bacmid. After transformation into $E$. coli DH10Bac, colonies were grown for $48 \mathrm{hrs}$. Colonies show up within $24 \mathrm{hrs}$ but take an additional day to develop a blue color. Large white colonies were selected and re-streaked onto a Tet-Kan-Gent-IPTG-X-gal plate.

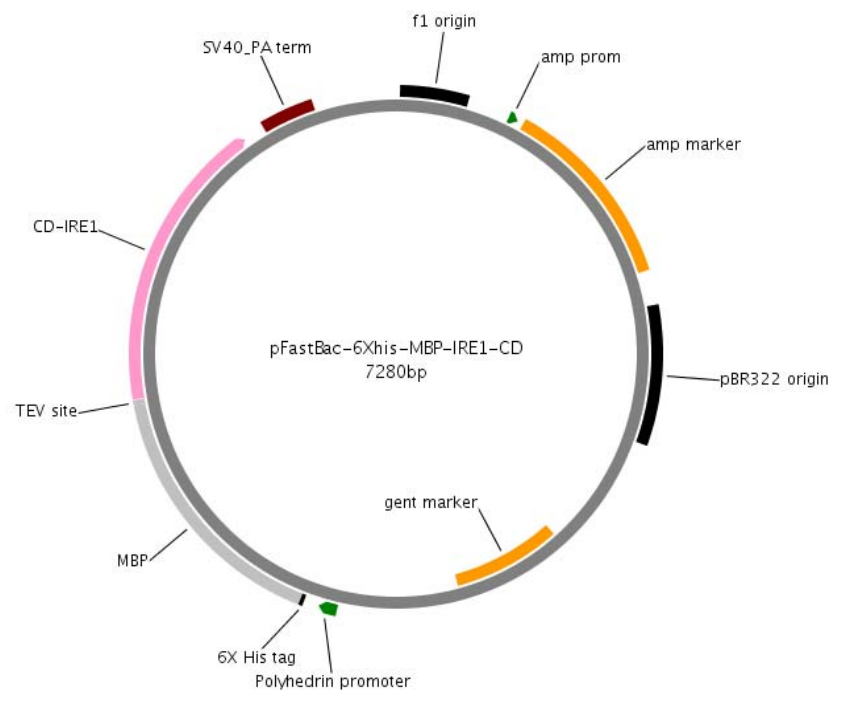


361

362

363

364

365

366

367

368

369

370

371

372

373

374

375

376

377

378

379

380

381

382

383

384

385

386

387

388

389

390

391

392

393

394

395

After this additional round of selection, a colony PCR was performed to make sure that IRE $1 \alpha-C D$ was incorporated into the recombinant bacmid (Figure 4). Primers specific to an internal region in IRE1 $\alpha$-CD were used. As expected, a band was seen in all of the white colonies picked, indicating that the gene of interest was inserted in the bacmid. Bacmids were prepped and sent for DNA sequencing. Once the IRE1 $\alpha-C D$ sequence was confirmed, glycerol stocks were made for future use (see Supplemental file).

\section{Colony number}

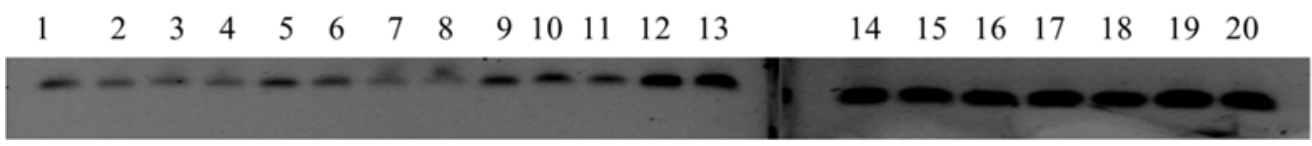

Figure 4: Colony PCR of white E. coli transformant colonies

The recombinant bacmid was extracted from $E$. coli $\mathrm{DH} 10 \mathrm{Bac}$ cells and precipitated with $100 \%$ isopropanol to obtain pure bacmid samples. Sf 21 cells were transfected and monitored for signs of infection for 5 days and multiple passages of viral titer. Figure 5 shows the Sf 21 cells changing on infection with $\mathrm{P} 3$ baculoviruses. The cells become larger in size, and the nuclei appear to occupy more of the cell. The Sf21 cells show more granularity as the infection progresses.
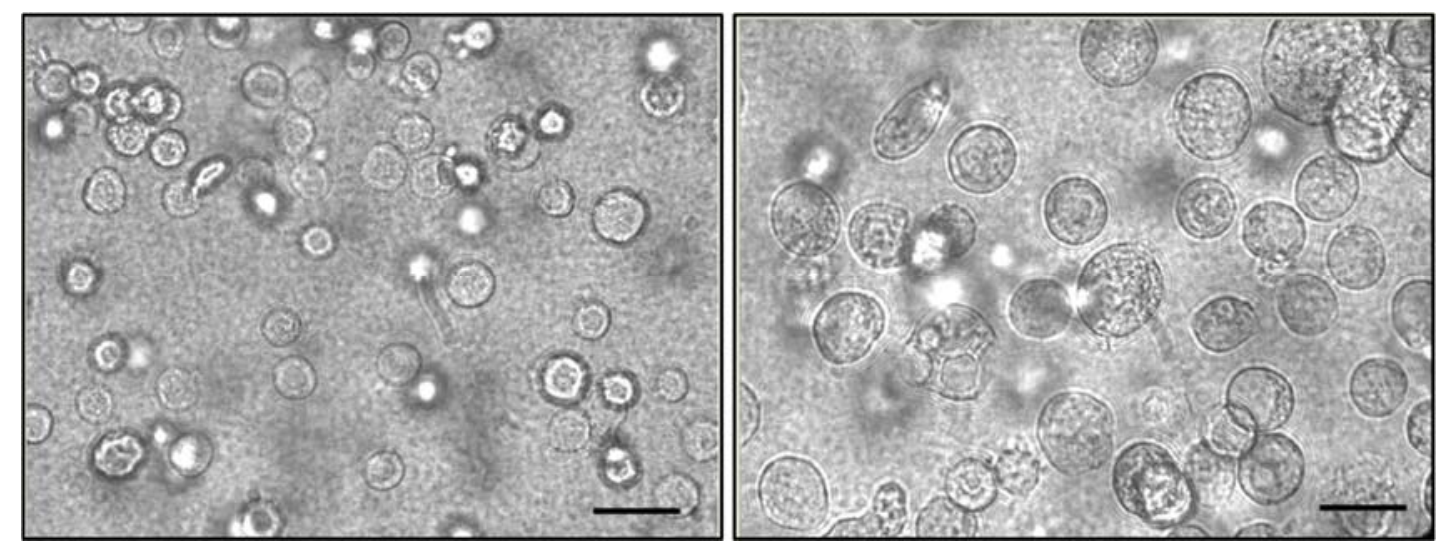

Figure 5: Signs of infection in untransfected Sf21 cells (left) and P3 treated Sf21 cells (right) for 24 hrs. Scale bar $=45 \mu \mathrm{m}$

We checked the expression of IRE $1 \alpha-C D$ after transfection by collecting cell lysate after P0 and P1 infections. Figure 6 shows a GelCode Blue-stained SDS-PAGE (8\%) of cell lysates after transfection and infection with baculoviruses to express IRE1 $\alpha-C D$. As evident in the figure, the IRE1 $\alpha$-CD protein is produced along with other contaminating insect cell proteins, also stained by GelCode Blue and therefore needs to be purified for downstream assays. The proportion of IRE1 $\alpha-C D$ protein expressed in P1 infected cells was more than P0 infected cells, reflecting the higher concentration of baculoviral titer. The baculovirus stock was amplified to P3 to obtain high protein expressing infected Sf21 cells.

The P3 viral supernatant was collected, filtered with a $0.22 \mu \mathrm{m}$ filter and stored at $4^{\circ} \mathrm{C}$ in the dark for subsequent infection. Sf 21 cells were passaged the day before infection so that they were in $\log$ phase at a density of $3 \times 10^{5}$ cells $/ \mathrm{mL}$. $150 \mu \mathrm{L}$ of $\mathrm{P} 3$ supernatant was added for each $\mathrm{mL}$ of Sf21 cells. The time required for the expression of a protein depends on each protein of interest expressed. 


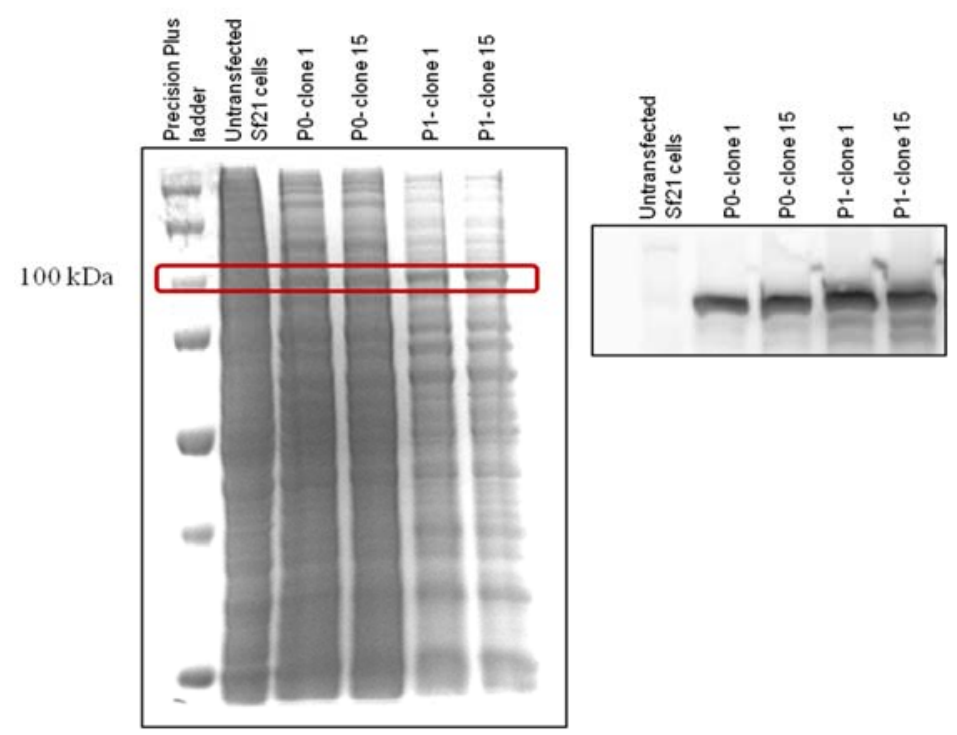

Figure 6: Expression of MBP- IRE1 $\alpha$-CD protein prior to purification. (Left) SDSPAGE of total protein lysate for untransfected Sf21 cells, P0 and P1 infected clones 1 and 15. The $100 \mathrm{kDa}$ band is marked and the putative 6X His- MBP-IRE1 $\alpha$-CD protein band is prominent in P1 infections. (Right) Western blot using an anti-IRE1 antibody

Figure 7 shows the western blot for the different time points throughout protein expression to determine the optimum time point for harvesting the cells. For IRE1 $\alpha-C D$, in P0 infected cells, maximum expression was observed at 96 hrs. Upon increasing infection titer by using P2 stocks, the overall level of protein expression increased. The optimal time point for harvesting was still after $96 \mathrm{hrs}$ of infection.

P0 infected Sf21 cells

Untransfected $24 \quad 48$
P2 infected Sf21 cells

\begin{tabular}{llllllllll}
\hline Untransfected & 24 & 48 & 72 & 96 & Untransfected & 24 & 48 & 72 & 96
\end{tabular}

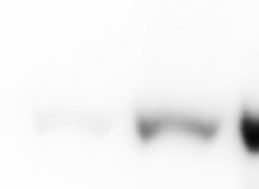

Figure 7: Expression of IRE1-CD protein. Western blot showing the time course of protein expression in P0 (left) and P2 (right) infected Sf21 cells using anti-IRE1a antibody

Once the viral titer and time for expression were optimized, the cell lysates were collected for purification of the protein. We used the MBP tag on the IRE1 $\alpha$-CD to aid in the purification. Filtered and clarified lysate was run through the MBPTrap column to obtain IRE $1 \alpha-C D$ protein. The protein was of $>85 \%$ purity based on densitometric analysis of the bands seen in an SDS-PAGE gel. Once IRE1 $\alpha$-CD is purified, it can be used for binding assays to determine binding partners for the protein [21]. Figure 8 below shows the various 
420

421

422

423

424

fractions from the purification process outlined in the manuscript. The addition of an MBPtag makes for a very specific purification. The yield of the expressed protein obtained after purification differs by the plasmids used, by baculoviral stocks and by the type of protein being expressed. The final volume of Sf21cells infected for scale-up can be adjusted based on the yield of protein required.

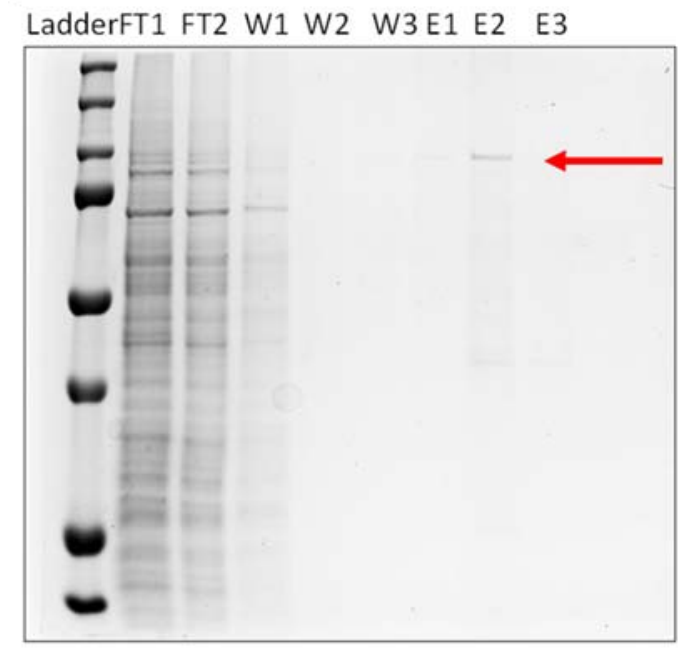

CD-IRE1 wild type Figure 8: A GelCode Blue stained SDS-PAGE showing the various fractions from the purification procedure of IRE1-CD. FT- Flowthrough, W- Wash fractions, E- Elute fractions. The ladder is the Precision Plus blue ladder (Bio-Rad, cat\# 1610373). The E2 fraction shows a pure protein band at $\sim 100 \mathrm{kDa}$ as expected

Sf21 insect cells combined with the pFastBac baculoviral system make a very robust, optimizable system for expression of eukaryotic proteins. MBP-IRE1 $\alpha$-CD was successfully expressed and purified from Sf21 cells. This protocol can be easily modified to express any mammalian protein in Sf21 insect cells by modifying the PCR primers shown in Table 4 for the desired CDS. Long term expression of the protein can be achieved by making frozen stocks of baculovirus infected Sf 21 cells. The MBP tag can be cleaved off using AcTEV protease if it interferes with downstream assays and the protein can be cleaned up using a NiNTA column. An AKTA-FPLC automated system can be used to aid in purification of higher volumes of cell lysate. If a secretion tag is used and the protein of interest is secreted in the media, a 5mL MBPTrap column can be used with the AKTA FPLC system to automate the purification process.

\section{Summary}

Further characterization of the expressed IRE1 $\alpha$ protein is required to establish its structure, phosphorylation status and in vitro XBP1 splicing activity conclusively. The phosphorylation status of the protein can be identified by various methods. Feldman et al., used mass spectrometry techniques to identify the phosphorylated sites on IRE1 $\alpha$ [22]. This technique in conjunction with a Phos-tag gel would lend more information on the ratio of phosphorylated to unphosphorylated species in the purified protein[23], [24]. Using the Phostag ligand developed by Fujifilm Wako-Chem, an SDS-PAGE gel can be used to separate phosphorylated proteins from unphosphorylated forms. The Phos-tag ligand binds to the phosphate group and slows down migration of the phosphorylated band. This leads to a 
452 separation of the phosphorylated and unphosphorylated species into separate bands. To 453 confirm that the band pattern is because of distinct phosphorylation, purified protein samples 454 can be treated with $\lambda$ - phosphatase enzyme with activity towards phosphorylated serine, 455 threonine and tyrosine residues. On treatment and subsequent application to a Phos-tag SDS456 PAGE gel, the slower migrating band should disappear. In vitro XBP1 splicing can be 457 assayed with a hairpin-RNA cleavage assay or by a fluorescence-based assay with a FRET458 paired oligonucleotide [18].

459 If the protein structure needs to be determined, circular dichroism or small-angle X460 ray scattering techniques can be used. Circular dichroism is a very useful tool to determine 461 secondary structure as well as native folding of expressed or fusion proteins. Specifically, 462 secondary structure can be determined using far-UV spectra and protein folding 463 characteristics can be determined by monitoring spectra at different temperatures or in the 464 presence of different denaturing agents [25].

465

466

467

468
Author Contributions: Conceptualization, A.O. and C.C.; Methodology, A.O.; Validation, A.O., G.J. and C.C; Writing - original draft preparation, A.O.; Writing-review and editing, A.O., G.J, C.C.; Funding and Supervision, C.C.

Funding: This research was funded by National Science Foundation, grant number CBET 1510895, CBET 1547518 and CBET 1802992.

Acknowledgments: The authors would like to thank Dr. Xiangshu Jin, Michigan State University for providing the Sf21 cell line for this work.

Conflicts of Interest: The authors declare no conflict of interest. The funders had no role in the design of the study; in the collection, analyses, or interpretation of data; in the writing of the manuscript, or in the decision to publish the results. 
479

480

481

482

483

484

485

486

487

488

489

490

491

492

493

494

495

496

497

498

499

500

501

502

503

504

505

506

507

508

509

510

511

512

513

514

515

516

517

518

519

520

521

\section{References}

[1] P. T. Wingfield, "Overview of the Purification of Recombinant Proteins," Curr. Protoc. Protein Sci., vol. 80, p. 6.1.1-6.1.35, 2016.

[2] S. Ventura, "Sequence determinants of protein aggregation: Tools to increase protein solubility," Microb. Cell Fact., vol. 4, no. 11, pp. 1-8, 2005.

[3] U. Rinas and J. E. Bailey, "Protein compositional analysis of inclusion bodies produced in recombinant Escherichia coli," Appl. Microbiol. Biotechnol., vol. 37, no. 5, pp. 609-614, 1992.

[4] X. Shi and D. Jarvis, "Protein N-Glycosylation in the Baculovirus-Insect Cell System," Curr. Drug Targets, vol. 8, no. 10, pp. 1116-1125, 2007.

[5] R. Chen, "Bacterial expression systems for recombinant protein production: E. coli and beyond," Biotechnol. Adv., vol. 30, no. 5, pp. 1102-1107, 2012.

[6] X. Gao, P. Yo, and T. K. Harris, "Improved yields for baculovirus-mediated expression of human His 6-PDK1 and His6-PKB $\beta /$ Akt2 and characterization of phospho-specific isoforms for design of inhibitors that stabilize inactive conformations," Protein Expr. Purif., vol. 43, no. 1, pp. 44-56, 2005.

[7] S. Müller, T. Sandal, P. Kamp-Hansen, and H. Dalbøge, "Comparison of expression systems in the yeasts Saccharomyces cerevisiae, Hansenula polymorpha, Klyveromyces lactis, Schizosaccharomyces pombe and Yarrowia lipolytica. Cloning of two novel promoters from Yarrowia lipolytica," Yeast, vol. 14, no. 14, pp. 12671283, 1998.

[8] J. C. Gupta, M. Jaisani, G. Pandey, and K. J. Mukherjee, "Enhancing recombinant protein yields in Escherichia coli using the T7 system under the control of heat inducible $\lambda \mathrm{P}(\mathrm{L})$ promoter," J. Biotechnol., vol. 68, no. 2-3, pp. 125-134, 1999.

[9] Y. Huang, Y. Li, Y. G. Wang, X. Gu, Y. Wang, and B. F. Shen, "An efficient and targeted gene integration system for high-level antibody expression," J. Immunol. Methods, vol. 322, no. 1-2, pp. 28-39, 2007.

[10] H. P. Sørensen and K. K. Mortensen, "Advanced genetic strategies for recombinant protein expression in Escherichia coli," J. Biotechnol., vol. 115, no. 2, pp. 113-128, 2005.

[11] G. L. Rosano and E. A. Ceccarelli, "Recombinant protein expression in Escherichia coli: Advances and challenges," Front. Microbiol., vol. 5, no. APR, pp. 1-17, 2014.

[12] A. Croset et al., "Differences in the glycosylation of recombinant proteins expressed in HEK and CHO cells," J. Biotechnol., vol. 161, no. 3, pp. 336-348, 2012.

[13] G. P. Subedi, R. W. Johnson, H. A. Moniz, K. W. Moremen, and A. Barb, "High Yield Expression of Recombinant Human Proteins with the Transient Transfection of HEK293 Cells in Suspension,” J. Vis. Exp., vol. 106, p. e53568, 2015.

[14] M. M. Van Oers, G. P. Pijlman, and J. M. Vlak, "Thirty years of baculovirus-insect cell protein expression: From dark horse to mainstream technology," J. Gen. Virol., vol. 96, no. 1, pp. 6-23, 2015.

[15] M. Merlin, E. Gecchele, S. Capaldi, M. Pezzotti, and L. Avesani, "Comparative evaluation of recombinant protein production in different biofactories: The green perspective," Biomed Res. Int., vol. 2014, 2014. 
522

523

524

525

526

527

528

529

530

531

532

533

534

535

536

537

538

539

540

541

542

543

544

545

546

547

548
[16] M. Schröder and R. J. Kaufman, “The Mammalian Unfolded Protein Response,” Annu. Rev. Biochem., vol. 74, pp. 739-789, 2005.

[17] R. L. Wiseman et al., "Flavonol activation defines an unanticipated ligand-binding site in the kinase-RNase domain of IRE1.," Mol. Cell, vol. 38, no. 2, pp. 291-304, Apr. 2010.

[18] F. Prischi, P. R. Nowak, M. Carrara, and M. M. U. Ali, "Phosphoregulation of Ire1 RNase splicing activity," Nat. Commun., vol. 5, pp. 1-10, 2014.

[19] B. Shrestha, C. Smee, and O. Gileadi, "Baculovirus Expression Vector System : An Emerging Host for High-Throughput Eukaryotic Protein Expression," in Methods in molecular biology (Clifton, N.J.), vol. 439, pp. 269-289.

[20] X. Dong, P. Stothard, I. J. Forsythe, and D. S. Wishart, "PlasMapper: A web server for drawing and auto-annotating plasmid maps," Nucleic Acids Res., vol. 32, no. WEB SERVER ISS., pp. 660-664, 2004.

[21] H. Cho et al., "Molecular mechanism by which palmitate inhibits PKR autophosphorylation," Biochemistry, vol. 50, no. 6, pp. 1110-1119, 2011.

[22] H. C. Feldman, M. Tong, L. Wang, R. Meza-acevedo, A. Theodore, I. Lebedev, ... D. J. Maly, "Structural and Functional Analysis of the Allosteric Inhibition of IRE1 $\alpha$ with ATP-Competitive Ligands," ACS Chem Biol, vol. 11, no. 8, pp. 2195-2205, 2016.

[23] L. Qi, L. Yang, and H. Chen, "Detecting and quantitating physiological endoplasmic reticulum stress," Methods in enzymology (1st ed., Vol. 490). Elsevier Inc., 2011.

[24] R. Volmer, K. van der Ploeg, and D. Ron, "Membrane lipid saturation activates endoplasmic reticulum unfolded protein response transducers through their transmembrane domains," Proceedings of the National Academy of Sciences, vol. 110, no. 12, pp. 4628-4633, 2013.

[25] N. J. Greenfield, "Using circular dichroism spectra to estimate protein secondary structure," Nat. Protocols, vol. 1, no. 6, pp. 2876-2890, 2006. 
549

550

551

552

553

554

555

556

557

558

559

560

561

562

563

564

565

566

567

568

569

570

571

572

573

574

575

576

577

578

579

580

\section{Supplemental file}

\section{Preparation of competent $E$ coli DH10Bac cells}

\section{Materials needed:}

i. E. coli $\mathrm{DH} 10 \mathrm{Bac}$ (streak from glycerol stock onto a Luria agar plate containing tetracycline/kanamycin/gentamycin, get isolated colonies and inoculate single colony) in LB broth containing tet $/ \mathrm{kan} /$ gent grown at $37^{\circ} \mathrm{C}$ at $200 \mathrm{rpm}$.

ii. Ice cold centrifuge tubes, P10, P200, P1000 tips, microcentrifuge tubes and cryovials

iii. Refrigerated centrifuge

iv. Dimethyl sulfoxide (DMSO)

v. FSB buffer: (Sterile filter through a $0.22 \mu \mathrm{m}$ filter and store at $4^{\circ} \mathrm{C}$ )

\begin{tabular}{|l|l|l|l|}
\hline Components & Company & Cat. no & Final concentration \\
\hline Potassium acetate $\mathrm{pH} 7.5$ & Sigma-Aldrich & P1190 & $10 \mathrm{mM}$ \\
\hline $\mathrm{MnCl}_{2}$ & Sigma-Aldrich & M1787 & $45 \mathrm{mM}$ \\
\hline $\mathrm{CaCl}_{2}$ & Sigma-Aldrich & C5670 & $10 \mathrm{mM}$ \\
\hline $\mathrm{KCl}$ & Sigma-Aldrich & P9541 & $100 \mathrm{mM}$ \\
\hline$\left[\mathrm{Co}\left(\mathrm{NH}_{3}\right)_{6}\right] \mathrm{Cl}_{3}$ & Sigma-Aldrich & 481521 & $3 \mathrm{mM}$ \\
\hline Glycerol & Sigma-Aldrich & G5516 & $10 \%$ \\
\hline
\end{tabular}

\section{Protocol:}

i. Grow E.coli DH10Bac cells overnight until the OD is between 0.3-0.6. The LB media should contain kanamycin and tetracycline at the working concentrations listed in Table 8 of the main text.

* It is very important not to overgrow the culture*

ii. Cool the cells in wet ice for 10-20 minutes.

\section{*From now on the cells should remain always ice cold*}

iii. Pellet the cells by centrifugation, $10 \mathrm{~min}$ at $2500 \mathrm{rpm}, 4^{\circ} \mathrm{C}$.

iv. Resuspend the cells gently in $24 \mathrm{ml}$ of ice-cold FSB.

v. Incubate on wet ice for 10-15 minutes.

vi. Pellet then cells again as above.

vii. Resuspend the cells in $8 \mathrm{ml}$ of cold FSB.

viii. Add $280 \mathrm{uL}$ DMSO.

ix. Incubate for 5 minutes on wet ice.

x. Add $280 \mathrm{uL}$ DMSO.

xi. Incubate for further 5 minutes on wet ice.

xii. Aliquot the cells in 200-400 uL batches to sterile single-use cryovials.

xiii. Store in $-80^{\circ} \mathrm{C}$.

*Do not store in liquid nitrogen* 
19 of 20

582

583

584

585

586

587

588

589

590

591

592

593

594

595

596

\section{Preparation of glycerol stocks for $E$ coli DH10Bac cells with recombinant bacmid}

\section{Materials needed:}

i. $\quad$ Glycerol (Sigma-Aldrich, cat \# G5516)

ii. Cryovials ( Sigma-Aldrich, cat\# 5000-0020)

\section{Protocol:}

i. Prepare a $60 \%$ glycerol solution in water. Filter sterilize using a $0.22 \mu \mathrm{m}$ filter or autoclave the solution at $121^{\circ} \mathrm{C}$ for 15 mins.

ii. Grow E. coli DH10Bac cells with recombinant bacmid in LB media for 14-16 hrs. The LB media should contain kanamycin, gentamicin and tetracycline at the working concentrations listed in Table 8 of the main text.

iii. Add $750 \mu \mathrm{L}$ of cells and $250 \mu \mathrm{L}$ of the glycerol solution to a cryovial.

iv. Invert a few times to mix properly.

v. Store at $-80^{\circ} \mathrm{C}$. 


\section{Preparation of recombinant bacmid from $E$. coli DH10Bac cells}

Materials needed:

i. PureLink HiPure Plasmid Miniprep kit (buffers R3, L7, N3) (ThermoFisher, cat\#

601

602

$$
\text { K210002) }
$$

ii. $100 \%$ isopropanol

Protocol:

i. For recombinant bacmids, use $15-25 \mathrm{~mL}$ of an overnight E. coli DH10Bac with recombinant bacmid grown in Luria Broth.

ii. Pellet the cells at $5000 \times \mathrm{g}$ for 7 minutes to harvest the cells. Remove all medium and wash with PBS if necessary.

iii. Add 0.4 mL Resuspension Buffer (R3) with RNase A to the cell pellet in the tube and resuspend the cells. Gently shake the tube until the cell suspension is homogeneous.

iv. Add 0.4 mL Lysis Buffer (L7). Place the cap on the tube and ensure it is secure. Mix gently by inverting the capped tube until the lysate mixture is thoroughly homogenous. Do not vortex.

v. Incubate the lysate at room temperature for 5 minutes. Do not exceed 5 minutes.

vi. Add $0.4 \mathrm{~mL}$ Precipitation Buffer (N3) and mix immediately by inverting the tube until the mixture is thoroughly homogeneous. Do not vortex. Centrifuge the lysate at $>12000 \mathrm{~g}$ for $10 \mathrm{mins}$ at RT.

*Don't load onto the column provided with the kit. It decreases yield of bacmid and does not increase the quality of bacmid obtained*

vii. Take the supernatant gently without disturbing the pellet Add $0.63 \mathrm{~mL}$ ice cold isopropanol to the supernatant. Mix well and incubate at RT for 15 mins.

viii. Centrifuge tube at $>12000 \mathrm{~g}$ for 30 mins

ix. Air dry the pellet for 10 mins, then resuspend the purified bacmid DNA in $60 \mathrm{uL}$ water.

x. Solubilize bacmid DNA for $1 \mathrm{hr}$ at $65^{\circ} \mathrm{C}$ or $4^{\circ} \mathrm{C}$ overnight. 